\title{
Characterization of the oral absorption of several aminopenicillins: Determination of intrinsic membrane absorption parameters in the rat intestine in situ
}

\author{
Doo-Man Oh a , Patrick J. Sinko ${ }^{\mathrm{a}, \mathrm{b}}$, and Gordon L. Amidon ${ }^{\mathrm{a}}$ \\ ${ }^{a}$ College of Pharmacy, The University of Michigan, Ann Arbor, MI 48109-1065 (USA) \\ and $^{b}$ Therapeutics Systems Research Laboratories, Inc., P.O. Box 7062, Ann Arbor, MI 48107 (USA)
}

(Received 28 May 1991)

(Modified version received 21 January 1992)

(Accepted 18 March 1992)

Key words: Absorption; Aminopenicillin; Amoxicillin; Ampicillin; Cyclacillin; Inhibition; Permeability

\section{Summary}

The absorption mechanism of several penicillins was characterized using in situ single-pass intestinal perfusion in the rat. The intrinsic membrane absorption parameters were determined using a modified boundary layer model (fitted value $+S$.E.): $J_{\max }^{*}=11.78 \pm 1.88 \mathrm{mM}, K_{\mathrm{m}}=15.80 \pm 2.92 \mathrm{mM}, P_{\mathrm{m}}^{*}=0, P_{\mathrm{c}}^{*}=0.75 \pm 0.04$ for ampicillin; $J_{\max }^{*}=0.044 \pm 0.018 \mathrm{mM}, K_{\mathrm{m}}=0.058 \pm$ $0.026 \mathrm{mM}, P_{\mathrm{m}}^{*}=0.558 \pm 0.051, P_{\mathrm{c}}^{*}=0.757 \pm 0.088$ for amoxicillin; and $J_{\max }^{*}=16.30 \pm 3.40 \mathrm{mM}, K_{\mathrm{m}}=14.00 \pm 3.30 \mathrm{mM}, P_{\mathrm{m}}^{*}=0$, $P_{\mathrm{c}}^{*}=1.14 \pm 0.05$ for cyclacillin. All of the aminopenicillins studied demonstrated saturable absorption kinetics as indicated by their concentration-dependent wall permeabilities. Inhibition studies were performed to confirm the existence of a nonpassive absorption mechanism. The intrinsic wall permeability $\left(P_{w}^{*}\right)$ of $0.01 \mathrm{mM}$ ampicillin was significantly lowered by $1 \mathrm{mM}$ amoxicillin and the $P_{w}^{*}$ of $0.01 \mathrm{mM}$ amoxicillin was reduced by $2 \mathrm{mM}$ cephradine consistent with competitive inhibition.

\section{Introduction}

The wall permeability, which is determined from steady-state perfusion experiments in the rat intestine, has been shown to be a key variable controlling oral drug absorption (Amidon et al., 1988). It was found that there is a good correlation between the fraction dose absorbed in hu-

Correspondence to: G.L. Amidon, Therapeutics Systems Research Laboratories, Inc., 540 Avis Drive, Suite A, Ann Arbor, MI 48108, U.S.A. mans and the dimensionless wall permeability $\left(P_{\mathrm{w}}^{*}\right)$, irrespective of the mechanism of absorption, and that $P_{w}^{*}$ might be useful for estimating oral drug absorption.

A modified boundary layer analysis has been developed by Johnson and Amidon (1988) in order to estimate the intrinsic membrane absorption parameters. To characterize the absorption mechanism of various $\beta$-lactam antibiotics, an in situ single-pass intestinal perfusion technique in rats was used and the intrinsic membrane parameters of some cephalosporins were determined (Hu et al., 1988; Sinko and Amidon, 1988). 
The $\beta$-lactam aminopenicillins, such as ampicillin, amoxicillin, and cyclacillin, are relatively well absorbed from the small intestine. Since they are ionized at the physiological $\mathrm{pH}$ and have low partition coefficients, it has been suggested that the mechanism of intestinal absorption of the aminopenicillins may be a saturable absorption process in the rat (Dixon and Mizen, 1977; Tsuji et al., 1977, 1978, 1981a,b; Kimura et al., 1978, 1983; Shindo et al., 1978; Iseki et al., 1984; Nakashima et al., 1984). However, there are conflicting reports in the literature on the absorption mechanism. Some investigators reported the passive absorption of ampicillin (Penzotti and Poole, 1974; Dixon and Mizen, 1977; Miyazaki et al., 1977; Kimura et al., 1978; Tsuji et al., 1981a; Iseki et al., 1984), amoxicillin (Dixon and Mizen, 1977; Miyazaki et al., 1977), and cyclacillin (Penzotti and Poole, 1974). Recently, human oral absorption data have suggested the existence of a capacity-limited transport system for aminopenicillins (Sjövall, 1985a).

In this report, the intrinsic parameters of some aminopenicillins were determined by carrying out single-pass perfusion expcriments in rats. Inhibition studies were performed to confirm the existence of carrier-mediated absorption of aminopenicillins including ampicillin.

\section{Experimental}

\section{Materials}

Ampicillin, amoxicillin, and urethane were purchased from Sigma Chemical Co. (St. Louis, MO). Cyclacillin was supplied by Wyeth-Ayerst (Philadelphia, PA). Polyethylene glycol (PEG) 3350 was obtained from Fisher Scientific (Fair Lawn, NJ), and $\left[{ }^{14} \mathrm{C}\right]$ PEG 4000 from New England Nuclear (Boston, MA). Citric acid and sodium chloride were purchased from Mallinckrodt, Inc. (Paris, KY). Monobasic potassium phosphate, acetonitrile, and dibasic sodium phosphate were obtained from J.T. Baker Chemical Co. (Phillipsburg, NJ). All chemicals were analytical or HPLC grades. Ecolite $(+)$, a liquid scintillation cocktail, was supplied by ICN Biomedicals, Inc. (Cleveland, $\mathrm{OH}$ ).
An appropriate amount of the compound to be studied was dissolved in a citric acid-dibasic sodium phosphate buffer, of which the $\mathrm{pH}$ was adjusted to 6.5 (Beckman pH meter, Fullerton, CA) and the osmolality to $300 \pm 5 \operatorname{mosM} / \mathrm{kg}$ (Wescor Model 5500 vapor pressure osmometer, Logan, UT). PEG $3550(0.01 \% \mathrm{w} / \mathrm{v})$ with a trace amount of $\left[{ }^{14} \mathrm{C}\right] \mathrm{PEG} 4000$ was added to the perfusion solution.

\section{In situ single-pass rat perfusion experiments}

Male Charles River rats (250-420 g, age 60-90 days) were fasted for $15-18 \mathrm{~h}$ prior to each experiment. Water was given ad libitum. Anesthesia was induced by an intraperitoneal injection of a $50 \%(\mathrm{w} / \mathrm{v})$ urethane solution $(1.6 \mathrm{~g} / \mathrm{kg})$. The jejunum was cannulated at $2-4 \mathrm{~cm}$ below the ligament of Treitz and about $10 \mathrm{~cm}$ distal to the first incision. The intestinal segment was perfused using a constant infusion pump (Harvard Apparatus, Model 931, South Natick, MA) for 2 h. The perfusate was maintained at $37 \pm 1^{\circ} \mathrm{C}$ by a water bath (Tek-Pro, American Dade, Miami, FL). During the experiment the rat was kept on a Precision slide warmer (GCA Co., Chicago, IL), and the abdomen was covered with a salinewetted paper towel and a piece of Parafilm (American Can Co., Greenwich, CT). The perfusion flow rate was 0.123 or $0.191 \mathrm{ml} / \mathrm{min}$. Steady state was achieved in approx. $30 \mathrm{~min}$, after which six samples were taken at 15 -min intervals. After the last sample was taken, the length of the intestine was measured by placing a piece of string along the intestine and measuring the string with a ruler.

For the inhibition studies, two segments of the rat jejunum were perfused simultaneously to serve as a control. The second segment was distal to the first segment. The data are reported as means ( \pm S.E.) from three to five rats with two to five determinations per rat.

\section{Analytical methods}

For the water flux measurement, $0.5 \mathrm{ml}$ of the sample was mixed with $15 \mathrm{ml}$ of scintillation cocktail. The samples were counted on a Beckman LS-9000 counter (Beckman Instruments Inc., Fullerton, CA). 
The samples were analyzed by high-performance liquid chromatography (IIPLC). The HPLC instrumentation consisted of a pump (Spectroflow 400, Kratos Analytical Instruments, Ramsey, $\mathrm{NJ}$ ), an automatic injector (Waters 712 WISP, Millipore Co., Milford, MA), a reversephase column (Partisil 10-ODS, $25 \mathrm{~cm}$, Whatman Inc., Clifton, NJ), a UV detector (Spectroflow 783 or 773, Kratos Analytic Instruments, Ramsey, NJ), and an integrator (Model 3390A, Hewlett-Packard Co., Avondale, PA). The mobile phase consisted of acetonitrile and $0.01 \mathrm{M}$ monobasic potassium phosphate $(\mathrm{pH} 6.1)$ in the ratio of $10: 90$ and 5:95 for ampicillin and amoxicillin, respectively, and acetonitrile, methanol, and monobasic potassium phosphate in the ratio of 19:11:70 for cyclacillin. The flow rate was $1.2 \mathrm{ml} / \mathrm{min}$, and the UV wavelength was $215 \mathrm{~nm}$ for ampicillin and $225 \mathrm{~nm}$ for amoxicillin and cyclacillin. The concentration was determined from the peak height.

\section{Data Analysis}

\section{Water transport}

Assuming that $\left[{ }^{14} \mathrm{C}\right] \mathrm{PEG} 4000$ will not be absorbed from the intestine, the percentage of water transport per centimeter length perfused for each sample was calculated from

$\%$ water transport $/ \mathrm{cm}$

$$
=\frac{100}{L} \cdot \frac{\left(A_{\mathrm{o}}-A_{\mathrm{b}}\right)-\left(A_{\mathrm{m}}-A_{\mathrm{b}}\right)}{A_{\mathrm{m}}-A_{\mathrm{b}}}
$$

where $A_{\mathrm{o}}, A_{\mathrm{m}}$, and $A_{\mathrm{b}}$ represent the disintegrations per min (dpm) of the inlet, outlet, and blank samples, respectively.

Water transport below $0.5 \% / \mathrm{cm}$ of intestinal length was considered normal and experiments at higher rates of water transport were not used for the determination of the permeability parameters. The perfusate outlet concentrations were corrected using Eqn 1.

\section{Estimation of intrinsic membrane parameters}

The intrinsic membrane absorption parameters were estimated using a modified boundary model approach developed by Johnson and Amidon (1988). Assuming that the difference between the rate of mass flowing into and out of the intestine is equal to the rate of mass absorbed, the dimensionless * effective wall permeability, $P_{\text {eff }}^{*}$, is calculated from the steady-state perfusion results:

$P_{\mathrm{eff}}^{*}=\frac{1-\left(C_{\mathrm{m}} / C_{\mathrm{o}}\right)}{4 \mathrm{Gz}}$

where $C_{\mathrm{o}}$ and $C_{\mathrm{m}}$ represent the inlet and outlet perfusate concentrations, respectively, and the Graetz number $* *, \mathrm{Gz}$, is defined as

$\mathrm{Gz}=\frac{\pi D L}{2 Q}$,

where $D$ denotes the diffusion coefficient, $L$ is the length of the intestine perfused, and $Q$ represents the fluid flow rate. The dimensionless aqueous permeability, $P_{\mathrm{aq}}^{*}$, is estimated from the film model approximation to the boundary layer results:

$P_{\mathrm{aq}}^{*}=\frac{1}{A \cdot \mathrm{Gz}^{1 / 3}}$,

where

$A=\left\{\begin{array}{rl}10.00 \mathrm{Gz}+1.010 & 0.004 \leqslant \mathrm{Gz} \leqslant 0.01 \\ 4.50 \mathrm{Gz}+1.065 & 0.010 \leqslant \mathrm{Gz} \leqslant 0.03 \\ 2.50 \mathrm{Gz}+1.125 & 0.030 \leqslant \mathrm{Gz}\end{array}\right.$

The wall concentration, $C_{w}$, and the dimensionless wall permeability, $P_{\mathrm{w}}^{*}$, are then calculated as follows:

$$
\begin{aligned}
& C_{\mathrm{w}}=C_{\mathrm{o}}\left(1-\frac{P_{\mathrm{eff}}^{*}}{P_{\mathrm{aq}}^{*}}\right) \\
& P_{\mathrm{w}}^{*}=\frac{P_{\mathrm{eff}}^{*}}{\left(1-\frac{P_{\mathrm{eff}}^{*}}{P_{\mathrm{aq}}^{*}}\right)} .
\end{aligned}
$$

\footnotetext{
* The multiplication of the parameter by $R / D$ results in the dimensionless parameter where $R$ is the radius of the intestine and $D$ denotes the diffusion coefficient.

* In the engineering literature $\mathrm{Gz}$ is traditionally defined as the inverse of Eqn 3.
} 
The dimensionless flux at steady state, $J_{\mathrm{ss}}^{*}$, is expressed as:

$J_{\mathrm{ss}}^{*}=P_{\mathrm{w}}^{*} \cdot C_{\mathrm{w}}$,

and for a combination of carrier and passive transport mechanisms $P_{\mathrm{w}}^{*}$ is assumed to be of the form:

$P_{\mathrm{w}}^{*}=\frac{J_{\max }^{*}}{K_{\mathrm{m}}+C_{\mathrm{w}}}+P_{\mathrm{m}}^{*}$,

where $J_{\max }^{*}$ and $K_{\mathrm{m}}$ are the maximal flux and the intrinsic Michaelis constant for the carrier transport, respectively, and $P_{\mathrm{m}}^{*}$ represents the intrinsic passive membrane permeability. The dimensionless carrier permeability, $P_{c}^{*}$ is defined as

$P_{\mathrm{c}}^{*}=\frac{J_{\max }^{*}}{K_{\mathrm{m}}}$

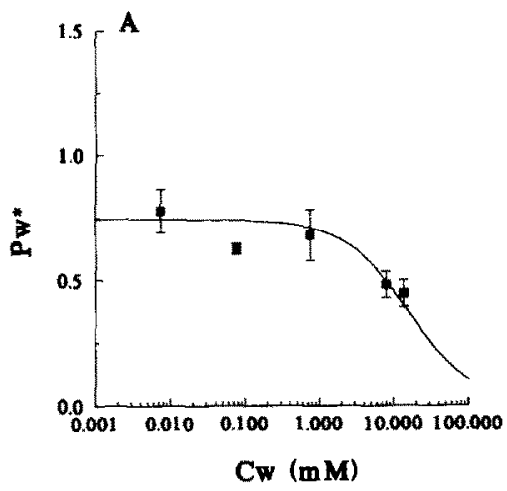

From Eqns 9 and 10,

$$
P_{\mathrm{w}}^{*}=\frac{P_{\mathrm{c}}^{*}}{\left(1+\frac{C_{\mathrm{w}}}{K_{\mathrm{m}}}\right)}+P_{\mathrm{m}}^{*}
$$

The corrected concentration ratio $\left(C_{\mathrm{m}} / C_{0}\right)$ was kept between 0.85 and 0.95 to estimate the permeability parameters (Johnson and Amidon, 1988).

Estimation of the aqueous diffusion coefficients

The diffusion coefficients used in the evaluation of the permeabilities were calculated according to the Hayduk-Laudie expression (Reid et al., 1977):

$D=13.26 \times 10^{-5} \eta^{-1.4} V_{\mathrm{A}}^{-0.589}$

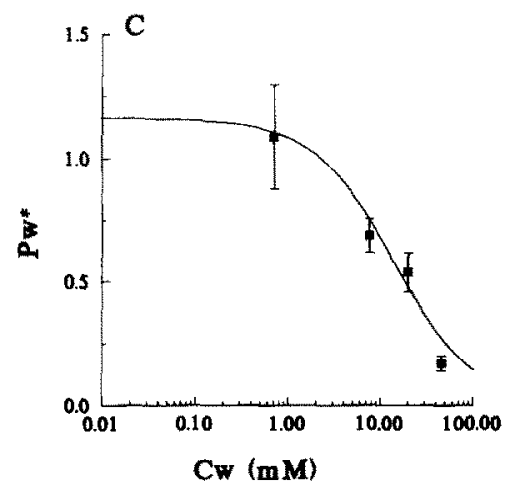

Fig. 1. Intrinsic wall permeability $\left(P^{*}\right)$ vs wall concentration $\left(C_{w}\right)$ of ampicillin $(A)$, amoxicillin (B), and cyclacillin $(C)$ in rat jejunum: ( $)$ experimental data (mean \pm S.E.) from three to five rats with two to five determinations per rat; $(\longrightarrow$ 
where $\eta$ denotes the viscosity of water $(0.6915 \mathrm{cP}$ at $\left.37^{\circ} \mathrm{C}\right), V_{\mathrm{A}}$ is the solute molal volume at normal boiling point $\left(\mathrm{cm}^{3} / \mathrm{g}\right.$ per mol), and $D$ denotes the binary diffusion coefficient at infinite dilution $\left(\mathrm{cm}^{2} / \mathrm{s}\right)$. Molal volumes were estimated using Schroeder's additive method. The values of $V_{\mathrm{A}}$ and $D$ are 315 and $0.00045 \mathrm{~cm}^{2} / \mathrm{min}$ for ampicillin, 322 and $0.00044 \mathrm{~cm}^{2} / \mathrm{min}$ for amoxicillin, and 315 and $0.00045 \mathrm{~cm}^{2} / \mathrm{min}$ for cyclacillin, respectively.

\section{Results and Discussion}

Intrinsic wall permeabilities of ampicillin, amoxicillin, and cyclacillin show a dependence on concentration, suggesting the existence of a saturable absorption mechanism in rat jejunum (Fig. 1). The experimental data were fitted to Eqn 9 or 11 using a weighted nonlinear regression to obtain the absorption parameters (Sinko and Amidon, 1988). A summary of the intrinsic absorption parameters is given in Table 1 . The intrinsic carrier permeabilities of ampicillin $(0.75 \pm 0.04)$ and amoxicillin $(0.76 \pm 0.09)$ are shown to be about the same, but less than that of cyclacillin $(1.14 \pm 0.05)$. The $K_{\mathrm{m}}$ of amoxicillin is several hundred times lower than that of ampicillin and cyclacillin, suggesting a higher affinity to the carrier transport system. A similar result for amoxicillin in rat intestine was reported by Nakashima et al. (1984). Amoxicillin exhibits significant passive transport in addition to the carrier-mediated pathway. A different experimental result for amoxicillin was reported (Sinko, 1988). It is not yet clear why the permeability profiles of ampi-

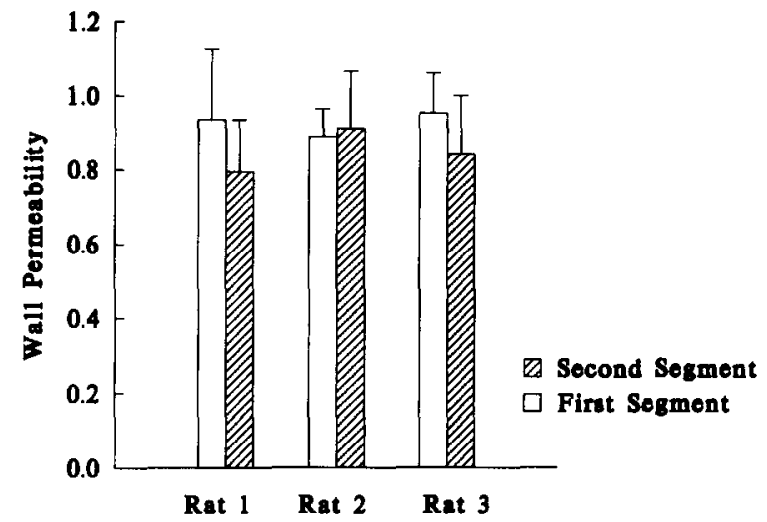

Fig. 2. Differences of the intrinsic wall permeabilities of 0.01 $\mathrm{mM}$ ampicillin between two rat jejunum segments (mean \pm S.E. from two to five determinations). The $p$ value from a paired $t$-test was 0.267 .

cillin and amoxicillin are different even though their structures are similar.

There are few reports on carrier-mediated transport of ampicillin in rat intestine. Shindo et al. (1978) reported that the absorption of ampicillin in rat intestinal loop showed a tendency toward saturation at a dose above $3 \mathrm{mg}$ per loop which was about $15 \mathrm{mM}$. It was shown that the intestinal absorption of cephradine and cephalexin was inhibited by ampicillin to some extent as well as by amoxicillin and cyclacillin (Miyazaki et al., 1982). The results of the present study indicate that the primary absorption mechanism of ampicillin in rat intestine is nonpassive.

The inter-rat variation can cause difficulty in estimating permeability when the compound has a relatively low $P_{w}^{*}$. To minimize this problem, two segments of rat jejunum were used to obtain

\section{TABLE 1}

Summary of the intrinsic wall permeability parameters for several penicillins in the rat intestine in situ

\begin{tabular}{lcclc}
\hline Compounds & $\begin{array}{l}J_{\max }^{*} \\
(\mathrm{mM})\end{array}$ & $\begin{array}{l}K_{\mathrm{m}} \\
(\mathrm{mM})\end{array}$ & $P_{\mathrm{m}}^{*}$ & $P_{\mathrm{c}}^{*}$ \\
\hline Ampicillin & $11.78 \pm 1.88^{\mathrm{a}}$ & $15.80 \pm 2.92$ & $\mathrm{ND0}{ }^{\mathrm{b}}$ & $0.75 \pm 0.04$ \\
Amoxicillin & $0.044 \pm 0.018$ & $0.058 \pm 0.026$ & $0.558 \pm 0.051$ & $0.757 \pm 0.088$ \\
Cyclacillin & $16.30 \pm 3.40$ & $14.00 \pm 3.30$ & $\mathrm{ND}$ & $1.14 \pm 0.05$ \\
\hline
\end{tabular}

\footnotetext{
a Fitted value \pm S.E.

b $\mathrm{ND0}=$ not different from zero.
} 
paired data. Fig. 2 shows that the difference of $P_{\mathrm{w}}^{*}$ of $0.01 \mathrm{mM}$ ampicillin between two segments was not significant $(p=0.267)$, suggesting the homogeneous distribution of a transport system throughout the rat jejunum. Similarly, the permeabilities of amoxicillin and cyclacillin showed no differences between two segments. For inhibition studies two segments were used alternately for the compound alone and the compound with an inhibitor.

Mutual inhibition studies on the absorption of $\beta$-lactam antibiotics and/or some dipeptides have shown that they share at least one carrier-mediated system (Kimura et al., 1978; Miyazaki et al., 1982; Iseki et al., 1984; Nakashima et al., 1984; Inui et al., 1988; Sinko and Amidon, 1989).

The results of coperfusion of ampicillin and amoxicillin are presented in Table 2 . The concentration of amoxicillin used as an inhibitor was 1 $\mathrm{mM}$ which is much higher than its $K_{\mathrm{m}}$ value. The $P_{\mathrm{w}}^{*}$ of $0.01 \mathrm{mM}$ ampicillin was significantly lowered by amoxicillin $(p=0.014)$. Kimura et al. (1978) reported that the simultaneous perfusion of 0.1 or $1.0 \mathrm{mM}$ amoxicillin did not inhibit the absorption of $0.1 \mathrm{mM}$ ampicillin. Ilowever, the variability in $P_{\mathrm{w}}$ is high and the paired studies used in this report are more sensitive to differences. Table 3 shows that the $P_{\mathrm{w}}^{*}$ of $0.01 \mathrm{mM}$ amoxicillin was significantly reduced by $2 \mathrm{mM}$ cephradine. It has been reported by Iseki et al. (1984) that the absorption of amoxicillin is significantly inhibited by cyclacillin, cephradine, and cephalexin, and that the inhibitory tendency of ampicillin on amoxicillin absorption is also ob-

TABLE 2

Inhibition of wall permeability of ampicillon $(0.01 \mathrm{mM})$ by co-perfusion with $1 \mathrm{mM}$ amoxicillin in the rat jejunum

\begin{tabular}{llll}
\hline Rat & \multicolumn{2}{l}{ Wall permeability $\left(P_{\mathrm{w}}^{*}\right)$} & Difference $^{\mathrm{b}}$ \\
\cline { 2 - 3 } & Without inhibitor & With inhibitor & \\
\hline 1 & $1.41 \pm 0.17^{\mathrm{a}}$ & $1.10 \pm 0.14$ & 0.31 \\
2 & $1.10 \pm 0.03$ & $0.82 \pm 0.04$ & 0.28 \\
3 & $0.74 \pm 0.09$ & $0.63 \pm 0.08$ & 0.11 \\
4 & $1.12 \pm 0.21$ & $0.91 \pm 0.12$ & 0.21 \\
\hline
\end{tabular}

a Mean \pm S.E. from two to five determinations.

${ }^{b} p<0.02$ by a paired $t$-test.
TABLE 3

Inhibition of wall permeability of amoxicillin $(0.01 \mathrm{mM})$ by co-perfusion with $2 \mathrm{mM}$ cephradine in the rat jejunum

\begin{tabular}{llll}
\hline Rat & \multicolumn{2}{l}{ Wall permeability $\left(P_{\mathrm{w}}^{*}\right)$} & Difference $^{\mathrm{b}}$ \\
\cline { 2 - 3 } & Without inhibitor & With inhibitor & \\
\hline 1 & $1.37 \pm 0.22^{\mathrm{a}}$ & $0.99 \pm 0.14$ & 0.38 \\
2 & $1.27 \pm 0.04$ & $0.95 \pm 0.17$ & 0.32 \\
3 & $1.45 \pm 0.06$ & $1.22 \pm 0.14$ & 0.23 \\
\hline
\end{tabular}

Mean \pm S.E. from two to five determinations.

${ }^{b} p<0.02$ hy a paired $t$-test

served in the rat. Dose-dependent absorption of amoxicillin (Spyker et al., 1977; Sjövall et al., 1985b) and ampicillin (Magni et al., 1978; Sjövall, 1979) has been observed in the human and the interaction between aminopenicillins investigated (Sjövall et al., 1985). Their findings and our results support the contention that the $\beta$-lactam aminopenicillins are absorbed via a carrier-mediated process combined with a parallel passive process and that there exists a common carrier system for $\beta$-lactam antibiotics.

In summary, our results have shown that the wall permeabilities of ampicillin, amoxicillin, and cyclacillin are concentration-dependent in rat jejunum. For inhibition studies, two segments of rat jejunum were used for reducing inter-rat variations. Inhibition studies confirmed the existence of a carrier-mediated mechanism of aminopenicillins.

\section{Acknowledgements}

The authors would like to thank Wyeth-Ayerst for supplying cyclacillin. This work was supported in part by NIGMS Grant GM37188.

\section{References}

Amidon, G.L., Sinko, P.J. and Fleisher, D., Estimating human oral fraction dose absorbed: A correlation using rat intestinal membrane permeability for passive and carrier-mediated compounds. Pharm. Res., 5 (1988) 651-654.

Dixon, C. and Mizen, L.W., Absorption of amino penicillins from everted rat intestine. J. Physial., 269 (1977) 549-559. 
Hu, M., Sinko, P.J., DeMeere, L.J. Johnson, D.A. and Amidon, G.L., Membrane permeability parameters for some amino acids and $\beta$-lactam antibiotics: application of the boundary layer approach. J. Theor. Biol., 131 (1988) $107-$ 114.

Inui, K., Okano, T., Maegawa, H., Kato, M., Takano, M. and Hori, R., $\mathrm{H}^{+}$coupled transport of p.o. cephalosporins via dipeptide carriers in rabbit intestinal brush-border membranes: difference of transport characteristics between cefixime and cephradine. J. Pharmacol. Exp. Ther., 247 (1988) 235-241.

Iseki, K., Iemura, A., Sato, H., Sunada, K., Miyazaki, K. and Arita, $T$., Intestinal absorption of several $\beta$-lactam antibiotics. V. Effect of amino- $\beta$-lactam analogues and dipeptides on the absorption of amino- $\beta$-lactam antibiotics. $J$. Pharm. Dyn., 7 (1984) $768-775$.

Johnson, D.A. and Amidon, G.L., Determination of intrinsic membrane transport parameters from perfused intestine experiments: a boundary layer approach to estimating the aqueous and unbiased membrane permeabilities. J. Theor. Biol. 131 (1988) 93-106.

Kimura, T., Endo, H., Yoshikawa, M., Muranishi, S. and Sezaki, H., Carrier-mediated transport systems for aminopenicillins in rat small intestine, J. Pharm. Dyn., 1 (1978) 262-267.

Kimura, T., Yamamoto, T., Mizuno, M., Suga, Y., Kitade, S. and Sezaki, H., Characterization of aminocephalosporin transport across rat small intestine. J. Pharm. Dyn., 6 (1983) 246-253.

Magni, L., Sjövall, J. and Syvalahti, E., Comparative clinical pharmacology of bacampicillin and high oral doses of ampicitlin. Infection, 6 (1978) 283-289.

Miyazaki, K.. Ogine, O., Nakano, M. and Arita, T., Intestinal absorption mechanisms of ampicillin derivatives in rats. I: Intestinal absorption of ampicillin derivatives. Chem. Pharm. Bull., 25 (1977) 246-252.

Miyazaki, K., Ohtani, K., Umeniwa, K. and Arita, T., Intestinal absorntion of several $\beta$-lactam antibiotics. III: Competitive inhibition behavior among zwitterionic $\beta$-lactam antibiotics in the intestinal absorption. J. Pharm. Dyn., 5 (1982) $555-563$.

Nakashima, E., Tsuji, A., Kagatani, S. and Yamana, T., Intestinal absorption mechanism of amino- $\beta$-lactam antibiotics. III: Kinetics of carrier-mediated transport across the rat intestine in situ. J. Pharm. Dyn., 7 (1984) 452-464.

Penzotti, S.C. and Poole, J.W., Transport mechanisms of $\beta$-lactam antibiotics across everted rat gut. J. Pharm. Sci., 63 (1974) 1803-1806.

Reid, R.C., Prausnitz, J.M. and Sherwood, T.K., The Proper- ties of Gases and Liquids, 3rd Edn, McGraw Hill, New York, 1977, pp. 57-59; 567-582.

Shindo, H., Fukuda, K., Kawai, K. and Tanaka, K., Studies on intestinal absorption of pivampicillin and species difference in the intestinal esterase activity. J. Pharm. Dyn., 1 (1978) $310-323$.

Sinko, P.J., Predicting oral drug absorption in man for compounds absorbed by carrier-mediated and passive absorption processes, Ph.D. Thesis, The University of Michigan, Ann Arbor, 1988.

Sinko, P.J. and Amidon, G.L., Characterization of the oral absorption of $\beta$-lactam antibiotics. I: Cephalosporins: determination of intrinsic membrane absorption parameters in the rat intestine in situ. Pharm. Res., 5 (1988) 645-650.

Sinko, P.J. and Amidon, G.L., Characterization of the oral absorption of $\beta$-lactam antibiotics. II: Competitive absorption and peptide carrier specificity. J. Pharm. Sci., 78 (1989) 723-727.

Sjövall, J., Dose dependence in human absorption of aminopenicillins. Infection, 7 (1979) s458-s462.

Sjövall, J., Alvắn, G. and Westerlund, D., Oral cyclacillin interacts with the absorption of oral ampicillin, amoxicillin, and bacampicillin. Eur. J. Clin. Pharmacol., 29 (1985a) 495-502.

Sjövall, J., Alván, G. and Westerlund, D., Dose-dependent absorption of amoxicillin and bacampicillin. Clin. Pharmacol. Ther., 38 (1985b) 241-250.

Spyker, D.A., Rugloski, R.J., Vann, R.L. and O'Brien, W.M., Pharmacokinetics of amoxicillin; dose dependence after intravenous, oral, and intramuscular administration. $A n$ timicrob. Agents Chemother, 11 (1977) 132-141.

Tsuji, A., Nakashima, E., Kagami, I. and Yamana, T., Intestinal absorption mechanism of amphoteric $\beta$-lactam antibiotics I: Comparative absorption and evidence for saturable transport of amino- $\beta$-lactam antibiotics by in situ rat small intestine, J. Pharm. Sci., 70 (1981a) 768-772.

Tsuji, A., Nakashima, E., Kagami, I. and Yamana, T., Intestinal absorption mechanism of amphoteric $\beta$-lactam antibiotics. II: Michaelis-Menten kinetics of cyclacillin absorption and its pharmacokinetic analysis in rats. $J$. Pharm. Sci., 70 (1981b) 772-777.

Tsuji, A., Nakashima, E., Kagami, I., Asano, T., Nakashima, R. and Yamana, T., Kinetics of Michaelis-Menten absorption of amino-penicillins in rats, J. Pharm. Pharmacol, 30 (1978) 508-509.

Tsuji, A., Nakashima, E., Kagami, I., Honjo, N. and Yamana, T., Effect of dose-concentration on the absorption of amoxicillin and ampicillin from the rat intestine. J. Pharm. Pharmacol, 29 (1977) 707-708. 